Peer-Reviewed Article

ISSN: 2162-3104 Print/ ISSN: 2166-3750 Online

Volume 7, Issue 3 (2017), pp. 555-582

(C) Journal of International Students

http://jistudents.org/

doi:10.5281/zenodo. 570023

\title{
Why Do International Students Avoid Communicating with Americans?
}

\author{
I-Ching Wang \\ Teachers College, Columbia University, USA \\ Janet N. Ahn \\ William Paterson University, USA \\ Hyojin J. Kim \\ Teachers College, Columbia University, USA \\ Xiaodong Lin-Siegler \\ Teachers College, Columbia University, USA
}

\begin{abstract}
We explore how the communication concerns of non-native English speakers (NNS) and Americans relate to their perceptions of each other and decisions to interact. NNS identified their concerns in communicating with Americans, the perceived causes of their concerns, and the strategies they would employ to address these concerns. Americans noted their perceptions of NNS' (heavy and mild) accents and identified factors that influence their perceptions of NNS and decisions to communicate with NNS. Results revealed that the more NNS attribute their communication concerns to Americans' bias, the more likely they would avoid interacting with Americans. Results also suggested that Americans show a more favorable attitude toward mild accent NNS. We discuss the implications these findings have for international education and future research.
\end{abstract}

Keywords: communication, ESL, foreign accent, intercultural competence, perceived bias

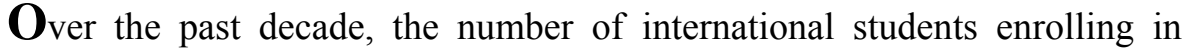
higher education in America has been growing rapidly (Institute of International Education, 2015). Approximately 5 million international students are enrolled in American colleges and universities (OECD, 2015) and the number is projected to reach 8-10 million by the year 2020 (Forest, 2007; Phakiti, Hirsh \& Woodrow, 2013). This fast growing educational 
globalization has brought both advantages and challenges to international education in the United States.

International students, who have been previously educated in environments culturally and socially different from their domestic peers, constitute an important source of cultural and language diversity, thus providing valuable intellectual resources to international education (Lee, 2016; Luo \& Jamieson-Drake, 2013; Hegarty, 2014). Presumably, the presence of international students exposes domestic students to different cultures, and this interaction between the two parties could lead to the development of social networks that are mutually beneficial in terms of the exchange of information, ideas, and support in the future (Andrade, 2009; Luo \& Jamieson-Drake, 2013).

Yet, many international students find that such desirable outcomes, especially with respect to the development of social networks, are not obtained at the level of their expectations (Brown, 2009). Gareis (2012) surveyed 454 international students who are non-native English speakers (NNS) and found that almost 40 percent of them reported having no close American friends but would like to have more meaningful interactions with Americans. Gareis also found that international students from East Asian countries had the least positive friendship experience in the United States than those from English speaking countries and Northern and Central Europe. These findings suggest that there is a breakdown in communication between NNS and Americans.

NNS commonly report having low confidence in their spoken English, low willingness to communicate (WTC) in English, and fear of negative evaluations, such as leaving faulty impressions and being judged unfavorably by others (Liu \& Jackson, 2008; 2011). NNS' reluctance to communicate with Americans not only impedes NNS' learning and disrupts smoother transitioning into U.S. universities but also costs both NNS and Americans' opportunities to enrich their respective experiences (Gareis, 2012; Hegarty, 2014). For example, NNS lose opportunities to develop sociolinguistic competence of American English (knowing how to appropriately speak and respond to different people in various contexts), which often requires informal and colloquial practice with Americans (Carrier \& Tatum, 2006). Furthermore, limited interactions with Americans would lead NNS to experience greater anxiety when they encounter situations where they have to speak in English or communicate with Americans. Having this greater anxiety may in turn lead them to associate these situations as anxiety-provoking, impairing their cognitive performance, and thereby lead to a dissatisfactory interaction (Coward \& Miller, 2010; Horwitz, Horwitz, \& Cope, 1986). On the other hand, for Americans, little interaction with NNS curtails their opportunities to learn different cultures and perspectives. Many Americans are likely to work with 
people from different countries or cultural backgrounds when they enter the workforce (Krajewski, 2011). Therefore, having exposure to different accents, cultures, and ways of thinking is especially helpful for Americans to develop intercultural awareness and effective intercultural communication skills, which are necessary to develop in today's globalized society (Dede, 2010; Morreale \& Pearson, 2008).

Although extensive research has been done to address issues related to teaching NNS the academic literacy skills they will need to succeed in higher education (Brandt, 2009; Sheppard, Rice, Rice, Drummond-Sardell, \& Soelberg, 2015), there has been little to no consideration of how NNS' communication concerns and in tandem, how Americans' perceptions of NNS' spoken English relate to NNS' communication behaviors. This oversight is puzzling since perceptions of communication from both sides of the interaction are equally important to understand and improve NNS' communication with Americans. The present study sought to close the gap on this oversight by examining both NNS and Americans' communication concerns. By focusing on both perspectives, we hope to understand factors that relate to NNS' communication concerns and raise awareness of interventions that can be employed to improve NNS' communication with Americans.

\section{LITERATURE REVIEW}

\section{Knowledge and Skills That Are Important for Oral Communication}

Oral communication, at its most basic level, refers to the spoken interaction between people (Sharma, 2008). This interaction is a complex process that involves multiple elements such as the purpose of the conversation, the roles and the relative status of the interlocutors, interlocutors' cultural background, facial expressions, and tone of voice (Rahman, 2010). These elements determine whether or not the interlocutors' intended messages are well transmitted, interpreted, and received (Rahman, 2010).

Several factors are often suggested to impact one's oral communication ability, such as grammatical knowledge of the language, social and cultural knowledge of the people who speak the language, and speaking skill (Sharma, 2008). Grammatical knowledge refers to one's understanding of grammar, vocabulary, sounds of letter and syllables, pronunciation of words, intonations, and stress (Rutherford, 2014). To communicate in a language orally, one must understand how words are pronounced and arranged to form sentences. Furthermore, knowing how sentences are structured in particular ways to generate meaning also enables one to understand and use the language structure accurately and fluently. Without grammatical knowledge, one will encounter difficulty in expressing 
him/herself and will not be understood clearly, all which can impede one's oral communication ability.

In addition to grammatical knowledge, one must also know what is socially and culturally acceptable by the speakers of the language. Social and cultural knowledge about Americans allows NNS to understand the ways language is shaped by the cultural norms, rules, and customs (TingToomey, Gu, \& Chi, 2007). This knowledge enables speakers to interpret others' messages more accurately and make appropriate comments in various social contexts. The lack of social and cultural knowledge can lead to communication breakdowns and prevent people from further interactions (Daim et al., 2012; Rizq, 2015). For example, in the United States, "How are you?" is often used as a greeting to say hello to acquaintances and strangers. The person who greets you may not be entirely interested in the actual answer. NNS, without knowing American culture, can mistake this greeting for a question and answer it with sincerity. Such a misunderstanding can make for an awkward interaction where NNS might feel embarrassed, disrespected, and hesitant to further interact with Americans after finding out that the Americans are not truly interested in their responses. Also, "Break a leg!" is an idiom to wish people luck. Without any prior American cultural background, it is difficult for NNS to interpret this phrase from its literal meaning. These examples display how NNS' lack of social and cultural knowledge of American people and culture can lead to communication breakdown.

Successful oral communication also depends on speaking skill. Speaking refers to the actions of constructing meanings in spoken language. It is an interactive process that involves receiving, processing, and producing information (Brown, 2007; Saeed, Khaksari, Eng, \& Ghani, 2016). Different from reading or listening, which often involves receptive skills, speaking also requires productive skills (Bailey, 2006). For example, when reading or listening, we recall the meanings of the received words to make sense of them; whereas, when speaking, we not only need to receive and process incoming messages but also produce appropriate and comprehensible responses. Furthermore, speaking often requires speakers to communicate spontaneously with others which gives speakers little time to construct, reflect, and revise (Richards, 2008). The productive and interactive skills required of spoken English make speaking more anxietyprovoking and difficult to acquire relative to the other traditional skills of language use (reading, listening, and writing) (Hashimi, 2011; Zhiping \& Paramasivam, 2013).

In sum, oral communication is a complex process that involves the integration of the aforementioned knowledge and skills. These elements are interdependent and lacking any one of them can impede learners from achieving effective oral communication. In the following section, we detail 
how communicating in a second language (L2) adds an additional layer of challenge for NNS.

\section{Communicating in a Second Language}

Beyond basic communication competencies, the multifaceted nature of L2 communication makes it particularly difficult for NNS (Terui, 2012). Limited English proficiency, cultural shock, and perceived discrimination all impose challenges to NNS' communication in L2 (Kelly \& Moogan, 2012; Lee \& Rice, 2007; Newsome \& Cooper, 2016). Cultural barriers, for example, could lead to misunderstanding and uneasiness $(\mathrm{Wu}$, Garza, \& Guzman, 2015; Wu, Yen, \& Marek, 2011). Wu, et al. (2015) found that Chinese and Korean participants both complained about the length they have to wait for a scheduled appointment, which was unusual in their countries and this led them to feel confused.

Furthermore, NNS' prior formal educational experiences may be deterrents for their engagement in conversations with native English speakers (NES). For example, Lee (2011) found that East Asian students, in their home countries, seldom speak or ask questions spontaneously in class out of fear of challenging the authority of the teacher or losing face in front of their peers if they provide wrong answers. Lee suggested that such classroom cultural differences may affect East Asian students' learning styles and interactions in English-medium academic environment in the United States. Sawir (2005) also found that NNS' prior English learning experiences and beliefs about language learning instilled during schooling influence NNS' communication behaviors. In NNS' home nations, there was a common focus on grammar, reading, and writing in English teaching and learning. NNS did not have many opportunities to learn conversational skills nor speak the language. NNS' belief about grammar being the most important aspect in English learning may shape their communication behavior and limit their conversational development (Tang \& Tian, 2015).

To compound the barriers that already exist in L2 communication, NNS often show low WTC in English. WTC is defined as "the probability of speaking when free to do so" (MacIntyre, 2007). Many L2 acquisition researchers consider WTC a critical component in language instruction (Bernales, 2012; MacIntyre, 2007). WTC is expected to facilitate NNS' English acquisition because it leads to an increased opportunity in authentic L2 use, which is regarded as a necessary condition for L2 acquisition (MacIntyre \& Legatto, 2011). NNS who have high WTC are more likely to use L2 in actual communication and accelerate L2 acquisition (Kang, 2005). WTC can also ease international students' psychological adjustment and improve international students' academic performance and professional success in the United States (Andrade, 2006; MacIntyre, 2007; MacIntyre \& Legatto, 2011). In Yashima and Tanaka's (2001) study of international 
Japanese students studying in the United States, the authors found that students who have high WTC show better psychological adjustment than those who have low WTC. Students who are more willing to communicate with their host family and domestic students learn more English and make more friends.

\section{Factors that Affect Non-Native English Speakers' Willingness to Communicate}

There are a few factors that may affect NNS' ability and WTC with NES such as NNS' tendency to solely associate within their own groups; NNS' insufficient social and cultural knowledge of the English speaking community; and NNS' fear and anxiety of speaking English. First, NNS tend to associate with people who speak the same first language (Kalocsai, 2009; Kaypak \& Ortactepe, 2014; Kim, 2006). Prior to studying in the United States, many NNS learned English as a foreign language (EFL) in their countries. In EFL context, English is not the dominant language and NNS have very few opportunities to speak English outside of these classes. Additionally, the format in which these classes are typically taught (i.e., in large classes and lecture-style teaching) gives NNS inadequate time to practice English speaking.

As a result, many NNS cannot express themselves in spoken English and thereby are unwilling to communicate with NES. This unwillingness also limits NNS' opportunity to produce English outputs in authentic contexts, which subsequently impedes their English acquisition. Previous research has shown a significant correlation between English improvement and the amount of English outputs that Englsh as a second language (ESL) learners produce (Mitchell, Myles, \& Marsden, 2013; Swain, 2005). Swain (2005) asserts that language output is not only the product of learning but also the learning process in itself. Therefore, producing the target language is important for language learners' language acquisition. When communicating with NES, NNS get to test their hypotheses about English usage, receive feedback, and identify areas they need to explore further in English (Lightbown \& Spada, 2006). It is through these interactive practices that NNS' communicative competence is developed (Chang \& Goswami, 2011) but an unwillingness to engage hampers acquisition and development.

Secondly, many NNS come to the United States with insufficient cultural knowledge of Americans. Rawlings and Sue (2013), for example, found that international students are often not prepared for the challenges they will encounter associated with cultural differences and English communication. Before coming to the United States, one major goal for NNS to learn English is to get good grades on English tests and be admitted into an American university. The examination guided instruction often 
overly focuses on the linguistic knowledge of English and has led to failure in learning communicative English and cultural knowledge of the English speaking community (Wu et al., 2011). Moreover, many EFL teachers tend to lack cultural knowledge of the English speaking community and have little experience of living in English speaking countries; therefore they are less inclined to cover cultural topics in their curriculum (Butler, 2011; Ozsevik, 2010). As a result, NNS often report having limited understanding of American culture and customs and not knowing what to talk about with Americans (Sherry, Thomas, \& Chui, 2010). Lack of cultural knowledge of the English speaking community can lead to embarrassing mistakes in communication. Such mistakes may confuse or offend NNS and in part threaten NNS' sense of competence (Brown, 2007), making communications with NES more difficult or undesirable.

Thirdly, the fear and anxiety NNS experience in speaking English may prevent them from communicating with NES. As Horwitz et al. (1986) asserted, foreign language learning probably poses the greatest threats to one's identity than any other field of study because one's performance is constantly evaluated by others and himself/herself. It challenges one's selfconcept as a capable individual and inevitably causes negative psychological states such as fear and anxiety. When asked to speak in English, NNS who are competent in their first language may feel reduced to childlike levels and consider English speaking a threatening situation and choose to remain silent than to risk appearing foolish (Gluszek \& Dovidio, 2010; Swain, 2013). NNS' fear of making mistakes and negative evaluations may lead to a loss of self-esteem which dampens WTC and decreases motivation to acquire the language (Coward \& Miller, 2010; Li \& Lu, 2011). Terui (2012) found that many NNS pretend they do (or do not) understand the conversational content exchanged with Americans to protect their selfesteem and cope with their anxiety. These affective dimensions of L2 learning deserve more attention because they might influence how NNS behave in future encounters where they interact with native speakers (Swain, 2013). That is, if NNS perceive their communication experience with NES positively, they would be more likely to initiate conversations with NES in the future. However, if NNS perceive it negatively, they would stay away from NES to avoid negative evaluations from NES.

All these factors potentially threaten NNS' ability and WTC with NES. Apparently, NNS' communication difficulty with NES is related not only to NNS' lack of linguistic and cultural knowledge but also their socialpsychological states (i.e., NNS' fear and anxiety). And yet, despite the gravity of this issue in communication breakdown, there is limited research that investigates how NNS' social-psychological communication concerns are related to NNS' communication with NES. The listed factors mainly emphasize NNS' experiences and perceptions of the communication but the 
literature is nearly silent on the simultaneous experience and perceptions of both NNS and NES. This oversight is puzzling because communication is an interactive and dynamic interaction that involves two parties. Considering both NNS and NES' communication concerns is equally important to understand the scope of NNS' communication with NES. Thus, our research aimed to shed light on this important aspect of NNS' communication.

This study is mostly exploratory in nature and focuses on this main research question: How do NNS and Americans (NES) perceive their communication with each other and how do these perceptions relate to NNS' communication with Americans? Under the umbrella of this question, we explore the following subsidiary questions. First, what are NNS' main concerns when communicating with Americans? Second, what do NNS perceive as causes to their communication concerns? Third, what strategies do NNS employ to address their communication concerns? Fourth, is there an association between NNS' perceived causes of their communication concerns and the types of strategies they adopt to communicate with Americans? And finally, are NNS' perceptions about how they are perceived by Americans justified?

To address these research questions, we first surveyed NNS' concerns in mastering and communicating in English with Americans by recruiting NNS from different foreign backgrounds where they reported on their communication concerns. We then developed a unique method to assess and elicit American's perceptions of East Asian NNS by having them listen to and rate their perceptions of heavy and mild accented East Asian NNS's spoken English. To consider NNS' side of communication concerns with Americans, we included a heterogeneous group of NNS (as opposed to solely focusing on East Asian NNS only to make comparable the two groups) for the following reasons: first, we would have severely limited our sample size if we excluded the non-East Asian NNS participants, thus being unable to meet the sample size requirement for completing correlations. Second, in piloting, we found there was no observable difference in the response patterns between East Asian and non-East Asian NNS participants.

To examine Americans' side of communication concerns with NNS, we focused on their perceptions of East Asian spoken English because East Asian students constitute the largest cohort of international students (44.4\%) coming to study in the United States (The Institute of International Education, 2014). Thus, understanding Americans' perceptions of East Asian NNS in particular would be valuable given that these interactions would be more frequent in comparison to other groups of international students. Second, prior research has shown that East Asian NNS, more so than NNS from other regions, typically encounter more communication difficulties with Americans (Gareis, 2012; Mak, 2011). East Asian NNS in particular are more likely to solely associate with people who speak the 
same first language as they do and actively avoid situations in which they need to communicate with Americans (Mak, 2011). Such an obvious avoidance from East Asian NNS signals that it is important to study how Americans respond to East Asian NNS in particular. For the abovementioned reasons, we focused on Americans' reactions to East Asian spoken English when considering their side of communication concerns.

\section{Participants}

\section{METHOD}

We recruited a total of 38 advanced level adult ESL learners (53\% East Asian, 26\% European, 18\% South American, 3\% African, 66\% female, $\left.M_{\text {age }}=27.15, S D_{\text {age }}=5.60\right)$ from a community English program in an urban college in the United States. This program offered English classes two hours a day for three times a week over a ten-week period in both spring and fall semesters. All the ESL learners had completed high school and some had post-secondary education in their countries of origin. They enrolled in the English program to prepare themselves for post-secondary studies or employment. Additionally, we recruited a total of 28 American participants who were NES (67.9\% European American, 10.7\% African American, 10.7\% Asian American, 10.7\% Latin American, 43\% female, Mage = 25.64, SDage $=7.69)$ from two different colleges in an urban city in the United States. All American participants were either pursing or had completed postsecondary education.

\section{Study Design}

The current study was descriptive and correlational in nature and had two components. The first component was a free-response Englishspeaking difficulty survey that was distributed to the 38 NNS participants during their class sessions. NNS participants were told that the purpose of this survey was to help develop better ESL programs. They were encouraged to answer the survey honestly without worrying about the accuracy of their English writing. They spent about 40 minutes to fill out this survey as well as their demographic information (e.g., age, gender, first language, L2, years of L2 learning, and country of origin). The second component of the study was the Accent-bias identification assessment that was distributed to the 28 American participants via emails from their current (or former) course instructors. The American participants were instructed to take the survey in a quiet place with headphones to ensure they can hear the voice clearly (details are provided below in Materials section). Participants spent about 40 minutes to complete the accent assessment and then filled out their demographic information (same as those for NNS). 


\section{Materials}

English-speaking difficulty survey for NNS. The 38 NNS participants answered three open-ended questions. They were asked to identity concerns in communicating with Americans: "Please list 3 difficulties you often encounter when communicating in English with Native English speakers." They were also asked to explain what might have caused the identified concerns: "Why did you have those difficulties? Please provide 3 reasons that might have caused the difficulties." And finally, they were asked to describe which strategies they have been using to address the identified concerns: "How did you address those difficulties? Please write 3 things you often do when encountering the difficulties."

Accent-bias identification assessment for American students. In order to assess American's attitudes toward East Asian accents, we adapted verbal-guise technique (Ahmed \& Abdullah, 2013; McKenzie, 2008) to design our accent-bias identification assessment. Verbal-guise technique is a variation of Lambert, Hodgson, Gardner, \& Fillenbaum's (1960) matchedguise technique which has been used to indirectly assess language attitudes toward different language varieties or different accents of English (Garrett, 2010; Kircher, 2015). In a standard verbal-guise test, participants listen to voice samples produced by different speakers and report their perceptions (e.g. affective and cognitive traits) of these speakers. The 28 American participants listened to voice samples of East Asian accents (one pair at a time) that varied in strength (i.e., mild and heavy accents) then assessed which one of the two speakers in the pair was higher on social status, intellectual competence, social attractiveness, and English proficiency.

To prepare these voice samples, ten American graduate students in an urban college were recruited as research assistants to select heavy- and mild- accented East Asian NNS speakers for the survey. The research assistants were provided voice samples of 20 East Asian NNS females and 20 East Asian NNS males reading an identical short passage from Time Magazine. They then rated all voice samples in terms of the speaker's accent strength from 1-10 $(1=$ mildest accent; $10=$ heaviest accent $)$. The two East Asian NNS female and male speakers (in total 4 speakers) that scored the highest in terms of heaviest accent strength were used to represent the heavy-accent category in the accent-bias identification survey. The two East Asian NNS female and male speakers (in total 4 speakers) that scored the lowest in terms of mildest accent strength were used to represent the mildaccent category in the survey.

The 28 American participants listened and assessed a total of 8 voice samples, one pair at a time (in total 8 pairs). The voice samples were paired in such a way that an American participant listened to one heavyaccented NNS and one mild-accented NNS that were of the same gender. For example, an American participant would listen to a heavy-accented 
female NNS and a mild-accented female NNS then move onto listen to a heavy-accented male NNS and a mild-accented male NNS, and so on.

Upon listening to each audio pair, American participants selected which one of the two speakers within that pair (either the mild-accented NNS or the heavy-accented NNS) was higher on social status (i.e., Who appears to be more educated?), intellectual competence (i.e., Who appears to be less intelligent? and Who is more likely to improve his/her English faster?), social attractiveness (i.e., Whom do you prefer to meet for a cup of coffee or dinner?), and English proficiency (i.e., Who is more difficult to understand?, Who can understand English better?, and Who can you communicate better with?). We rendered all the questions in dichotomous format and included some negative-keyed questions (i.e., Who appears to be less intelligent?) to reduce the chances of response bias in rating scale questions (e.g., extreme responding). We also administered a manipulation check to ensure that there was a clear difference between the heavy- and mild-accented NNS (i.e., Who has stronger accent?). The order of audio pairs was randomized and the order of questions in which participants assessed each of the voice samples was also counterbalanced across participants.

Finally, we interviewed all 28 American participants and asked them two questions at the end of the study. They were asked to enlist the two most important factors that influenced their decisions regarding how well they could communicate with a NNS. Also, they enlisted the two most important factors that influenced their decision regarding whether they were willing to spend any time with that person socially.

\section{DATA ANALYSIS}

English-speaking difficulty survey for NNS. Two trained raters coded the NNS participants' responses into three categories for each of the three respective questions. For the first question that asked about participants' communication concerns with American, the three most often occurring coding categories were regarding social psychological, cultural, and language related issues. For the second question that asked participants to identify causes to those specified concerns, the three most frequently occurring categories were regarding American's bias, limited contact with and knowledge of Americans, and English proficiency. And finally, for the last question that asked participants about the strategies they used to deal with the concerns, the three most frequently occurring categories were regarding avoidance, interaction, and improving English skills.

An interrater reliability analysis using the Kappa statistic was performed to determine consistency among the two raters' coding within each of the three questions (i.e., challenges, reasons, and coping strategy). 
For the first question, Kappa was 0.773 ( $\mathrm{p}<.0 .001), 95 \%$ CI $(0.669,0.877)$. For the second question, Kappa was 0.853 ( $\mathrm{p}<.0 .001), 95 \%$ CI $(0.771$, 0.935). For the last question, Kappa was 0.768 ( $p<.0 .001), 95 \%$ CI $(-0.232$, 1.768). These statistic values show that there was a substantial agreement between the two raters' coding for all three questions (Landis \& Koch, 1977).

Additionally, NNS' answers to each of the three questions were labeled (i.e. 1, 2, and 3) using the generated categories. For example, the three categories that were generated for the second question were labeled as such: (1) American's bias, (2) limited contact with and knowledge of Americans, and (3) English proficiency. If a participant responded to the second question by stating that: "Americans look down on me" then this response was labeled as a "1," whereas a response as "My English is not good" would have been labeled as a "3." Additionally, researchers coded the frequency of each response within a particular category. Thus, if for the second question a participant responded with "There are no Americans in my community" and "I am not familiar with American sports" then both these responses would be categorized under the second category with a frequency of " 2 ."

Accent-bias identification assessment for American students. When an American participant rated that one of the two NNS speakers (mild-accented or heavy-accented) was higher on a particular item (e.g., appears to be more educated), that speaker received a 1 whereas the speaker who was not chosen received a 0. For example, if an American participant rated that the mild-accented NNS speaker appeared to be more educated than the heavyaccented NNS speaker, then the former speaker received a 1 whereas the latter speaker received a 0 .

\section{RESULTS}

We administered a manipulation check to ensure that there was a clear difference between the heavy- and mild-accented NNS speakers. We found that across all audio pairs, there was a significant difference in the proportion of those who thought the heavy-accented East Asian NNS speaker had a stronger accent than the mild-accented East Asian NNS speaker, $\chi^{2}(1, N=224)=104.50, p<001, \varphi=.68$.

\section{English-speaking Difficulty Survey for NNS}

NNS' most frequently reported communication concern with Americans. Half of the English communication concerns raised by participants were regarding English language skills and the other half of the concerns mentioned were related to either social-psychological factors or cultural factors. 
NNS' perceived causes of their communication concerns with Americans. $41 \%$ of the attributions participants made about their difficulties in communicating with Americans were related to perceived bias and discrimination, $20 \%$ of the attributions were related to lacking interactions with and knowledge of NS, and $39 \%$ of the attributions were related to low English proficiency.

Strategies NNS have used to deal with their communication concerns. $45.5 \%$ responses were related to avoidance behaviors, $32.5 \%$ answers were related to interactions, and 22\% answers were related to improving English skills.

Correlations between perceived causes and strategies applied in the English-speaking difficulty survey. A Spearman's test was conducted to assess the correlations among NNS' identified communication concerns, perceived causes of their identified concerns, and the strategies they applied to address the concerns. Important to the current research agenda (how do NNS' perceptions of their communication concern relate to their communication with Americans) we specifically examined whether there was any correlation between NNS' perceived causes of their communication concerns and the types of strategies NNS adopted to communicate with Americans. Thus, although there are several significant correlations, we highlight only a couple that are central to our research question.

Table 1: Correlations among NNS' Identified Communication Concern with Americans, Perceived Causes of the Communication Concern, and Strategies Applied to Address their Communication Concern

\begin{tabular}{|c|c|c|c|c|c|c|c|c|c|}
\hline Variables & 1 & 2 & 3 & 4 & 5 & 6 & 7 & 8 & 9 \\
\hline \multicolumn{10}{|l|}{ Communication difficulty with Americans } \\
\hline 1 Social-psychological related & & & & & & & & & \\
\hline 2 Cultural related & -0.31 & & & & & & & & \\
\hline 3 Language related & $-0.68 * *$ & $-0.45 * *$ & & & & & & & \\
\hline \multicolumn{10}{|l|}{ Perceived causes } \\
\hline 4 Americans' bias & $0.84^{* *}$ & -0.14 & $-0.63^{* *}$ & & & & & & \\
\hline 5 Limited contact with and knowledge of Americans & -0.18 & -0.05 & 0.12 & -0.56 ** & & & & & \\
\hline 6 Limited English proficiency & $-0.91 * *$ & 0.16 & $0.72 * *$ & $-0.84 * *$ & 0.04 & & & & \\
\hline \multicolumn{10}{|l|}{ Strategies applied } \\
\hline 7 Avoidance & $0.86 * *$ & -0.03 & $-0.76 * *$ & $0.89 * *$ & -0.31 & $0.87 * *$ & & & \\
\hline 8 Interaction & $-0.49 * *$ & 0.14 & $0.35 * *$ & -0.65 & $0.37 *$ & $0.52 * *$ & $-0.71 * *$ & & \\
\hline 9 Improving English skills & $0.82 * *$ & 0.06 & $-0.80 * * *$ & $-0.71 * *$ & 0.09 & $0.81 * *$ & $0.83 * *$ & 0.20 & \\
\hline
\end{tabular}

Note: ${ }^{*} p<0.05 ; * * p<0.01$

Correlations between Americans' bias and strategies applied. Americans' bias positively correlates with avoidance strategy, $r_{\mathrm{s}}(38)=0.89, p<.01$ and negatively correlates with improving English skills, $r_{\mathrm{s}}(38)=-0.71, p<.01$. The more NNS participants perceived Americans' bias as the cause to their communication concerns, the more likely they would avoid having conversation with Americans and the less likely they would improve 
English skills.

\section{Correlations between limited contact with and knowledge of} Americans and strategies applied. We observed a positive correlation between limited contact with and knowledge of Americans (i.e., their cultural knowledge of Americans) and interaction strategy (i.e., they would talk to Americans more and approach them), $\operatorname{rs}(38)=0.37, \mathrm{p}<.05$. The more NNS participants perceived a lack in their cultural knowledge of Americans as a cause to their communication concern, the more likely they would approach Americans.

\section{Accent-bias Identification Survey for Americans}

In order to assess Americans' attitudes toward East Asian accents, we conducted a McNemar test for each of the seven questions of interest. As shown in Table 5, we observed that relative to the heavy-accented East Asian NNS, there was a significant difference in the proportion of those who thought the mild-accented East Asian NNS appeared to be more educated, $\chi^{2}$ $(1, N=224)=86.25, p<001, \varphi=.62$; more intelligent, $\chi^{2}(1, N=224)=$ 83.79, $p<001, \varphi=.61$; and more likely to improve his/her English, $\chi^{2}$ (1, $N$ $=224)=69.75, p<001, \varphi=.56$. Additionally, relative to the heavyaccented East Asian NNS, more American participants preferred to meet with the mild-accented East Asian NNS for coffee or dinner, $\chi^{2}(1, N=224)$ $=96.47, p<001, \varphi=.66$; thought the mild-accented NNS participants could understand English better, $\chi^{2}(1, N=224)=101.79, p<001, \varphi=.67$; and could communicate better, $\chi^{2}(1, N=224)=107.25, p<001, \varphi=.69$. Finally, American participants also believed that relative to the heavyaccented East Asian NNS, the mild-accented East Asian NNS was less difficult to understand, $\chi^{2}(1, N=224)=112.86, p<001, \varphi=.71$.

Additionally, in our interview data that asked American participants to list the two most important factors that influenced their decisions regarding how well they thought they could communicate with a NNS, we found that 24 of the 28 American participants (more than $85 \%$ ) believed that the strength of a NNS' accent mattered in their ability to communicate: "How easy it was to understand their accent" and "The clearer the accent the better." Other factors that were mentioned to affect their decision were their physical appearance and friendliness.

With respect to American participants' responses to name the two most important factors that influenced their decision to spend any time with a NNS socially, we found more that 23 of 28 participants $(82 \%)$ believed that NNS' accent mattered the most in making their decision. Other factors that were mentioned but only subordinate to accent were physical appearance, common interests, and friendliness.

In sum, the results suggest that accent indeed matters in Americans' perceptions about NNS. American participants are biased towards East 
Asian NNS with a heavy accent. Relative to the heavy-accented NNS, American participants tended to assess the mild-accented NNS as higher on social status, intellectual competence, social attractiveness, and English proficiency.

\section{DISCUSSION}

This study is one of few efforts that systematically investigated how both NNS and Americans (NES) perceive the communication concerns between the two parties. With respect to one side of the interaction in terms of NNS' perceptions, results indicated that NNS' perceived causes of their communication concerns with Americans correlated with the strategies they would adopt to communicate with Americans. The more a NNS perceived Americans' bias as the cause to his/her communication concern, the more likely he/she would avoid having conversations with Americans. Additionally, the more a NNS perceived limited contact with and knowledge of Americans as the cause to his/her communication concern, the more likely he/she would interact with Americans.

And, with respect to the other side of the interaction in terms of Americans' perceptions, relative to the heavy-accented NNS speakers, American participants viewed NNS with mild accents as more intelligent, more educated, and even expressed more interest in engaging in social interactions with the latter than the former. It seems American participants have a bias towards NNS with heavy accents. These findings provide ample support for the premise that social-psychological fear (i.e., the fear of making mistakes and being unfavorably evaluated) can powerfully impact NNS' WTC with Americans. We observed that this fear of negative judgment and discrimination from Americans were reported as one of the main causes to NNS' communication concerns with Americans. This finding suggests that fear of communicating could be as impactful to NNS' communication behaviors as language competence itself (e.g., grammar and vocabulary). These findings have important implications to research of intercultural competences development and teaching English as a L2 to international students. The implications, limitations of the current study, and future directions are discussed in the following sections.

\section{IMPLICATIONS}

Our findings have implications for several areas, particularly for intercultural competences development and teaching English as a L2.

\section{Intercultural competences development}

Research conducted on cross cultural adaptation, international job seeking and performance, and other forms of international contacts (e.g., immigration and refugee resettlement), clearly identify intercultural 
competences as a key capability for working and living effectively with people from different cultures (Bird, Mendenhall, Stevens, \& Oddou, 2010). Indeed, intercultural competence is essential for establishing effective and positive relations across cultural boundaries. As such, researchers' primary interests in examining intercultural competences arose out of people's difficulties in coping with practical problems encountered by living and working overseas (Aitken, 1973; Ruben, 1989; Torbiörn, 1982). These difficulties range from cultural shock, cultural adaptation to language learning, and communication effectiveness. The definitions of intercultural competence are many, and are centered around the aforementioned difficulties (Fantini \& Tirmizi, 2006; United Nations Educational, Scientific and Cultural Organization, 2013).

We contribute to this area of research by focusing on a very specific and critical aspect of intercultural competences, namely, intercultural communication competence. We used both self-report and behavioralperceptual assessment to identify intercultural communication difficulties by revealing voices from both NNS and Americans. By doing so, we hope to have a deeper and more focused explanation for intercultural communication challenges, an issue especially relevant in today's fast growing educational globalization.

It is clear that intercultural competences are far more than matters surrounding grammar, vocabulary, or even general cultural and social knowledge of the local culture. The attitudes, perceptions, and goals held by both international students and Americans might all be contributing factors to intercultural competences. For example, previous work has shown that learning about an individual person's life, beliefs, and struggles had strong emotional and cognitive effects on students' strategies for resolving intercultural disputes, whereas general cultural knowledge tended to strengthen stereotypes and previous opinions, and it did not lead to improved problem solving (Lin \& Bransford, 2010). As such, helping people develop intercultural competences involves not only strengthening their language skills, but also knowledge about self and others from the local culture. Byram, Gribcova, \& Starkey (1997) differentiated this knowledge from general knowledge about a specific culture and defined it as the "knowledge of social processes, and knowledge of the illustrations of those processes." They regarded it as a critical component to intercultural communication competence and stated that knowing "how people are likely to perceive you" is an example of this knowledge. For instance, in our informal interview with of over 50 international students, many of them report being perceived differently in their own country and in the United States (International students, informal interview at International Student Office, March 18, 2014). A few indicated that they were viewed as funny and social person in their own country. However, people perceive them as 
shy and isolated individuals in the United States. We opened up the conversation about how people in different cultures often have strikingly different construals of the self, and of others (Markus \& Kitayama, 1991) to help international students understand this divergence. Being social is defined quite differently in the United States than in other countries. As such, international students can't expect Americans to view them the same as people from their home country. One important way to acquire this new knowledge about self and others in a given local culture is through communication and interaction. This now leads to our discussion of teaching English as a L2 and how EFL instruction should be encouraged to include self-and-other perception management as a part of oral communication instruction.

\section{Teaching English as a second language to international students}

English proficiency is crucial for the development of intercultural communication competence but equally important is having an understanding of American culture and values. However, due to constraints such as test-driven curriculum and insufficient resources, EFL education has typically focused on grammar, vocabulary, reading, and writing. These knowledge and skills are no doubt very important; yet, issues that may rise from oral communication between people from different cultural and language backgrounds have not been emphasized in EFL curriculum. Little attention has been given to understanding the complex relationship between international students and Americans' communication concerns, and in turn, how these concerns relate to international students' motivation to communicate and interact with Americans.

Besides paying attention to international students' communication concerns, our results point to the importance of self-and-other perception management. According to our results, people's perceptions and beliefs about themselves, others, and their environment influence their WTC with others and their culture, and, as a result, their strategies to learn and utilize the new language. This means that shaping people's beliefs and perceptions can potentially affect their motivation and thereby their strategies to communicate with NES and vice versa. Many intercultural competences training programs tend to be foreigner-centered, focusing on educating foreigners who will go to the new culture (Lin \& Bransford, 2010). Rarely, do the training programs also include educating and shaping people's perceptions about the foreigners from the recipient cultures. As such, we have very little knowledge about how the attitudes and perceptions of people in recipient cultures affect foreigners' motivation and strategies to communicate with the new culture. An underlying assumption of the present study is that bridging cultural gaps and enhancing intercultural competences (via intercultural communication) is the joint responsibility of all participants (Lin, Schwartz, \& Bransford, 2007), and helping students take 
on a global perspective is an important goal to achieve in future research of both EFL instruction and intercultural competences development.

\section{LIMITATIONS}

Although the present work sheds light on an understudied but important issue, we acknowledge it is not without its limitations. The sample sizes of the current study are notably small (although the effect sizes observed were quite large) and only observed a specific demographic population of adult international students. It would be an important agenda to pursue in the future to replicate as well as to generalize these findings more broadly by using a larger sample size and a different population sample (perhaps younger students).

Additionally, it is important to note that while we surveyed the experiences of NNS from a variety of geographic and cultural regions, we only focused exclusively on Americans' perceptions of East Asian speakers' accents (as opposed to accents of speakers from various foreign backgrounds). As noted in the Present Research section, we have a variety of reasons for doing so (to meet the sample size requirement for correlation analysis, East Asian NNS report more communication difficulties with Americans than NNS from other regions, etc.), we strongly recommend that future research survey more rigorously whether American students' biases differ depending on the foreign accent (e.g., East Asian accents versus European accents) and if the reported communication concerns are different. In this vein, because we did not use the East Asian NNS participants from the English speaking difficulty survey as speakers for our voice samples in the Accent-bias identification assessment, we acknowledge that the design of the study was not experimentally controlled, thus limiting our ability to draw strong conclusions from the observed results.

For the assessments (the English speaking difficulty survey and the Accent-bias identification survey), we employed a self-report approach in the present study because they allow researchers to collect a wide range and better quality of intrapsychic information (e.g., thoughts and feelings) that is otherwise difficult to obtain (Paulhus \& Vazire, 2007). Moreover, participants are better able to contextualize when reporting on self-relevant information and, therefore, provide a more valid and conclusive report of their communication concerns (Paulhus \& Vazire, 2007). However, we acknowledge that there are limitations associated with using this approach. For example, socially desirable responding could be a disadvantage (Paulhus \& Vazire, 2007). NNS and Americans may exaggerate, fake, deny, defense, or self-favoring in the self-report survey or the interview to achieve socially desirable outcomes, manage others' impression of them, or deceive themselves. Though we tried to control the effects of socially desirable 
responding by maximizing the anonymity and confidentiality of the study, future research can utilize different experimental approaches that do not heavily rely on self-reports to improve the validity of participants' responses.

We also acknowledge that the way questions were posed to participants might have unintentionally biased their answers. By asking NNS only about their "concerns" or "difficulties" in their communication with Americans blurs us from knowing other aspects of NNS' communication with Americans (e.g., certain benefits or advantages) that are also important when examining NNS' communication with Americans. However, we emphasize that for the scope of the present study, we focused on one aspect of NNS' communication with Americans (i.e., concerns) since this domain can raise awareness of interventions that can be employed to improve NNS' communication with Americans.

\section{FUTURE DIRECTIONS}

Biases toward others have been known to affect people's learning and willingness to interact and communicate (Dovidio \& Gaertner, 2010). However, what is less known are the contributing factors to these biases. The current research suggests that accent might be one factor that contributes to biases and thus this area warrants more attention. Future studies can investigate if accent is more likely to lead to biases and unfavorable perceptions than poor and well-written English. In addition, knowing whether accent bias is universal or only targeted towards a particular group and people presents to be a fruitful area for future studies.

Another important factor that has not been examined deeply is how international students' goals affect their perceptions and motivation to develop intercultural communication competence. It is highly likely that international students who want to work and settle in the new culture, e.g., in America, may perceive and approach Americans more differently than those who decide to finish their schooling and move back home. Similarly, Americans who have the goal to collaborate and work with international students in their post college life may view and tolerate international students' accents differently than Americans who do not hold such goals.

It is clear that language knowledge alone does not ensure international students' competence in communicating with Americans. Concerns and perceptions about the communication from both parties may affect their interaction and communication, which is critical to intercultural competence development. The findings of the present study offer inviting opportunities for future researchers to develop a comprehensive framework for intercultural competence development. 
Appendix

\begin{tabular}{|c|c|c|}
\hline \multicolumn{3}{|c|}{ NNS' Most Frequently Reported Communication Concerns with Americans } \\
\hline Difficulties & Example quotes & n (\%) \\
\hline $\begin{array}{l}\text { Social- } \\
\text { psychological } \\
\text { related }\end{array}$ & $\begin{array}{l}\text { "I am afraid of making mistakes"; "I feel inferior } \\
\text { because I don't speak good English"; "People under- } \\
\text { stand me but pretend they don't cause I have an } \\
\text { accent"; "I get nervous when I have to speak English } \\
\text { and forget what to say" }\end{array}$ & $\begin{array}{l}29 \\
(25 \%)\end{array}$ \\
\hline $\begin{array}{l}\text { Cultural relat- } \\
\text { ed }\end{array}$ & $\begin{array}{l}\text { "I don't understand American jokes"; "We are not } \\
\text { used to talking a lot in classrooms (in Korea)" }\end{array}$ & $\begin{array}{l}29 \\
(25 \%) \\
\end{array}$ \\
\hline $\begin{array}{l}\text { Language re- } \\
\text { lated }\end{array}$ & $\begin{array}{l}\text { "I can't express myself well"; "I can’t understand } \\
\text { English well"; "Americans cannot understand me" }\end{array}$ & $\begin{array}{l}56 \\
(50 \%)\end{array}$ \\
\hline \multicolumn{3}{|c|}{ NNS' Perceived Causes of Their Communication Concern with Americans } \\
\hline Causes & Example quotes & n (\%) \\
\hline $\begin{array}{l}\text { American's } \\
\text { bias }\end{array}$ & $\begin{array}{l}\text { "Americans look down (on) other people"; "NS be- } \\
\text { lieve that we can never understand each other so they } \\
\text { don't listen to me"; "NS have stereotypes towards } \\
\text { Asians"; "Americans assume I speak English well } \\
\text { and assume I know the topics they are talking about" }\end{array}$ & $\begin{array}{l}46 \\
(41 \%)\end{array}$ \\
\hline $\begin{array}{l}\text { Limited con- } \\
\text { tact with and } \\
\text { knowledge of } \\
\text { Americans }\end{array}$ & $\begin{array}{l}\text { "I don't understand American culture well enough, I } \\
\text { could misunderstand them"; "There are no Ameri- } \\
\text { cans in my community" }\end{array}$ & $\begin{array}{l}24 \\
(20 \%)\end{array}$ \\
\hline $\begin{array}{l}\text { English profi- } \\
\text { ciency }\end{array}$ & $\begin{array}{l}\text { "I didn't learn English when I was young"; "My } \\
\text { English is not good"; "My vocabulary is small"; "It's } \\
\text { difficult to express myself in other languages"; } \\
\text { "Americans cannot understand my accent" }\end{array}$ & $\begin{array}{l}44 \\
(39 \%)\end{array}$ \\
\hline \multicolumn{3}{|c|}{ Strategies NNS Applied to Address the Communication Concern } \\
\hline Strategies & Example quotes & n (\%) \\
\hline Avoidance & $\begin{array}{l}\text { "I avoid having eye contact with Americans"; "I } \\
\text { avoid speaking with Americans"; "I ask other people } \\
\text { to speak English for me"; "I pretend I understand." }\end{array}$ & $\begin{array}{l}52 \\
(46 \%)\end{array}$ \\
\hline Interaction & $\begin{array}{l}\text { "I tell Americans that my English is not good and } \\
\text { ask them to repeat again"; "I try to use different } \\
\text { words to express myself"; "I practice speaking Eng- } \\
\text { lish with my English classmates more" }\end{array}$ & $\begin{array}{l}37 \\
(33 \%)\end{array}$ \\
\hline $\begin{array}{l}\text { Improving } \\
\text { English skills }\end{array}$ & $\begin{array}{l}\text { "I study more grammar"; "I read more English mag- } \\
\text { azine"; "I watch more English TV shows"; " I listen } \\
\text { to radio" }\end{array}$ & $\begin{array}{l}25 \\
(22 \%)\end{array}$ \\
\hline
\end{tabular}

Note: For each question, participants were asked to provide three answers with each of their answers coded into the different categories. Percentages reflect the percentage of total answers related to each category rather than the percentage of participants providing each answer 


\section{REFERENCES}

Aitken, N. D. (1973). The effect of the EEC and EFTA on European trade: A temporal cross-section analysis. The American Economic Review, 63(5), 881-892.

Ahmed, Z. T., \& Abdullah, A. N. (2013). The role of accent and ethnicity in the professional and academic context. International Journal of Applied Linguistics \& English Literature, 2(5), 249-258.

Andrade, M. S. (2006). International students in English-speaking universities: Adjustment factors. Journal of Research in International Education, 5(2), 131-154.

Andrade, M. S. (2009). The value of a first-year seminar: International students' insights in retrospect. Journal of College Student Retention: Research, Theory, \& Practice, 10(4), 483-506.

Bailey, K. M. (2006). Issues in teaching speaking skills to adult ESOL learners. In J. Comings, B. Garner, \& C. Smith (Eds.), Review of adult learning and literacy: Vol. 6. Connecting research, policy, and practice (pp. 113-164). Mahwah, NJ: Erlbaum.

Bernales, C. (2012). Towards a comprehensive concept of willingness to communicate: Learners' predicted and self-reported participation in the foreign language classroom. System, 56, 1-12.

Bird, A., Mendenhall, M., Stevens, M. J., \& Oddou, G. (2010). Defining the content domain of intercultural competence for global leaders. Journal of Managerial Psychology, 25(8), 810-828.

Brandt, C. (2009). Read, research and write: academic skills for ESL students in higher education. Greater London, London: SAGE Publications.

Brown, H. D. (2007). Principles of language learning and teaching (5th ed.). New York, NY: Pearson Education.

Brown, L. (2009). A failure of communication on the cross-cultural campus. Journal of Studies in International Education, 13(4), 439-454.

Butler, Y. G. (2011). The implementation of communicative and task-based language teaching in the Asia-Pacific region. Annual Review of Applied Linguistics, 31, 36-57.

Byram, M., Gribcova, B., \& Starkey, H. (2002). Developing the intercultural dimension in language teaching: A practical introduction for teachers. Strasbourg, France: Council of Europe.

Carrier, K. A., \& Tatum, A. W. (2006). Creating sentence walls to help Englishlanguage learners develop content literacy. The Reading Teacher, 60(3), 285-288.

Chang, M., \& Goswami, J. S. (2011). Factors affecting the implementation of communicative language teaching in Taiwanese college English classes. English Language Teaching, 4 (2), 3-12.

Coward, F. L., \& Miller, P. C. (2010). Navigating the graduate seminar discussion: A qualitative analysis of international students' experiences. International Journal of Communication, 4, 1013-1031.

Daim, T. U., Ha, A., Reutiman, S., Hughes, B., Pathak, U., Bynum, W., \& Bhatla, A. (2012). Exploring the communication breakdown in global virtual teams. International Journal of Project Management, 30(2), 199-212. 
Dede, C. (2010). Comparing frameworks for 21st century skills. 21st century skills: Rethinking how students learn, 20, 51-76.

Dovidio, J. F., \& Gaertner, S. L. (2010). Intergroup bias. In S. T. Fiske, D. T. Gilbert, \& G. Lindsey (Eds.), Handbook of Social Psychology: Vol 1 (5 $^{\text {th }}$ ed.) (pp.1084-1121). Hoboken, NJ :John Wiley \& Sons.

Fantini, A., \& Tirmizi, A. (2006). Exploring and assessing intercultural competence. World Learning Publications. Paper 1. http://digitalcollections.sit.edu/worldlearning_publications/1

Forest, J. J. F. (2007). Teaching and learning in higher education. In J. J. F. Forest \& P. G. Altbach (Eds.), International Handbook of Higher Education (pp. 347-375). Dordrecht, Netherlands: Springer.

Gareis, E. (2012). Intercultural friendship: Effects of home and host region. Journal of International and Intercultural Communication, 5(4), 309-328.

Garrett, P. (2010). Attitudes to language. Cambridge, United Kingdom: Cambridge University Press.

Gluszek, A., \& Dovidio, J. F. (2010). Speaking with a nonnative accent: Perceptions of bias, communication difficulties, and belonging in the United States. Journal of Language and Social Psychology, 29(2), 224-234.

Hashimi, M. (2011). Language stress and anxiety among the English language learners. Procedia - Social and Behavioral Sciences, 30, 1811-1816.

Hegarty, N. (2014). Where we are now-The presence and importance of international students to universities in the United States. Journal of International Students, 4(3), 223-235.

Horwitz, E. K., Horwitz, M. B., \& Cope, J. (1986). Foreign language classroom anxiety. The Modern Language Journal, 70(2), 125-132.

Institute of International Education. (2014). International students: All places of origin. Retrieved from http:/www.iie.org/Research-andPublications/Open-Doors/Data/International-Students/All-Places-ofOrigin/2013-15

Institute of International Education. (2015). International students: Enrollment trends. Retrieved from http://www.iie.org/Research-andPublications/Open-Doors/Data/International-Students/EnrollmentTrends\#.V_FDFcl-iT8

United Nations Educational, Scientific and Cultural Organization (UNESCO). (2013). Intercultural competences: Conceptual and operational framework. Paris, France: UNESCO.

Kalocsai, K. (2009). Erasmus exchange students: A behind-the-scenes view into an ELF community of practice. Journal of Applied Language Studies, 3(1), 25-49.

Kang, S. J. (2005). Dynamic emergence of situational willingness to communicate in a second language. System, 33(2), 277-292.

Kaypak, E., \& Ortactepe, D. (2014). Language learner beliefs and study abroad: A study on English as a lingua franca (ELF). System, 42, 355-367.

Kelly, P. \& Moogan, Y. (2012). Culture shock and higher education performance: Implications for teaching. Higher Education Quarterly, 66(1), 24-46.

Kim, S. (2006). Academic oral communication needs of East Asian international graduate students in non-science and non-engineering fields. English for Specific Purposes, 25(4), 479-489. 
Kircher, R. (2015). The matched-guise technique. In Z. Hua (Ed.), Research methods in intercultural communication: A practical guide (pp. 196-211). Hoboken, NJ: John Wiley \& Sons, Inc.

Krajewski, S. (2011). Developing intercultural competence in multilingual and multicultural student groups. Journal of Research in International Education, 10(2), 137-153.

Lambert, W. E., Hodgson, R. C., Gardner, R. C., \& FillenBaum, S. (1960). Evaluational reactions to spoken languages. Journal of Abnormal and Social Psychology, 60(1), 44-51.

Landis, J. R., \& Koch, G. G. (1977). The measurement of observer agreement for categorical data. Biometrics, 33, 159-174.

Lee, E. J. E. (2016). International and American students' perceptions of informal English conversations. Journal of International Students, 6(1), 14-34.

Lee, J. J., \& Rice, C. (2007). Welcome to America? International student perceptions of discrimination. Higher Education, 53(3), 381-409.

Lee, J. Y. (2011). English learning styles of students from East Asian countries: A focus on reading strategies. International Education Studies, 4(2), 75-81.

Lightbown, P. M., \& Spada, N. M. (2006). How languages are learned (3rd ed.). Oxford, NY: Oxford University Press.

Lin, X. D., \& Bransford, J. D. (2010). Personal background knowledge influences cross-cultural understanding. Teachers College Record, 112(7), 17291757.

Lin, X. D., Schwartz, D., \& Bransford, J. D. (2007). Intercultural adaptive expertise: Explicit and implicit lessons from Dr. Hatano. Human Development, 50(1), 65-72.

Liu, M., \& Jackson, J. (2008). An exploration of Chinese EFL learners' unwillingness to communicate and foreign language anxiety. Modern Language Journal, 92(1), 71-86.

Liu, M., \& Jackson, J. (2011). Reticence and anxiety in oral English lessons: a case study in China. In L. Jin \& M. Cortazzi (Eds), Researching Chinese learners: Skills, perceptions, and intercultural adaptation (pp. 119-137). Basingstoke, United Kingdom: Palgrave Macmillan.

Luo, J., \& Jamieson-Drake, D. (2013). Examining the educational benefits of interacting with international students. Journal of International Students, 3(2), 85-101.

MacIntyre, P. D. (2007). Willingness to communicate in the second language: Understanding the decision to speak as a volitional process. Modern Language Journal, 91(4), 564-576.

MacIntyre, P. D., \& Legatto, J. J. (2011). A dynamic system approach to willingness to communicate: Developing an idiodynamic method to capture rapidly changing affect. Applied Linguistics, 32(2), 149-171.

Mak, B. (2011). An exploration of speaking-in-class anxiety with Chinese ESL learners. System, 39(2), 202-214.

Markus, H. R., \& Kitayama, S. (1991). Culture and the self: Implications for cognition, emotion, and motivation. Psychological Review, 98(2), 224-253.

McKenzie, R. M. (2008). The role of variety recognition in Japanese university students' attitudes towards English speech varieties. Journal of Multilingual and Multicultural Development, 29(2), 139-153. 
Mitchell, R., Myles, F. M., \& Marsden, E. (2013). Second language learning theories (3rd ed.). New York, NY: Routledge.

Morreale, S. P., \& Pearson, J. C. (2008). Why communication education is important: The centrality of the discipline in the $21 \mathrm{st}$ century. Communication Education, 57(2), 224-240.

Newsome, L. K., \& Cooper, P. (2016). International students' cultural and social experiences in a British university: "Such a hard life [it] is here". Journal of International Students, 6(1), 195-215.

OECD. (2015). Education Database: ISCED-97, Foreign / international students enrolled (Edition 2014), OECD Education Statistics [Data file]. http://dx.doi.org/10.1787/5db3dac7-en

Ozsevik, Z. (2010). The use of communicative language teaching (CLT): Turkish EFL teachers' perceived difficulties in implementing CLT in Turkey (Unpublished master's thesis). University of Illinois at Urbana-Champaign, Urbana, Illinois.

Paulhus, D. L. \& Vazire, S. (2007). The self-report method. In R. W. Robins, R. C. Fraley, \& R. F. Krueger (Eds.), Handbook of research methods in personality psychology (pp. 224-239). New York, NY: Guilford.

Phakiti, A., Hirsh, D., \& Woodrow, L. (2013). It's not only English: Effects of other individual factors on English language learning and academic learning of ESL international students in Australia. Journal of Research in International Education, 12(3), 239-258.

Rahman, M. M. (2010). Teaching oral communication skills: A task-based approach. ESP World, 9(1), 1-11.

Rawlings, M., \& Sue, E. (2013). Preparedness of Chinese students for American culture and communicating in English. Journal of International Students, 3(1), 29-40.

Richards, J. C. (2008). Teaching listening and speaking: From theory to practice. New York, NY: Cambridge University Press.

Rizq, W. M. (2015). Teaching English idioms to L2 learners: ESL teachers' perspective. Culminating Projects in English (Unpublished master's thesis). St. Cloud State University, Minnesota.

Ruben, B. D. (1989). The study of cross-cultural competence: Traditions and contemporary issues. International Journal of Intercultural Relations, 13(3), 229-240.

Rutherford, W. E. (2014). Second language grammar: Learning and teaching (2nd ed.). New York, NY: Routledge.

Saeed, K. M., Khaksari, M., Eng, L. S., \& Ghani, A. M. A. (2016). The role of learner-learner interaction in the development of speaking skills. Theory and Practice in Language Studies, 6(2), 235-241.

Sawir, E. (2005). Language difficulties of international students in Australia: The effects of prior learning experience. International Education Journal, 6(5), 567-580.

Sharma, A. C. D. (2008). Communication skills and personality development. Maharashtra, India: Nirali Prakashan.

Sheppard, B., Rice, J., Rice, K., Drummond-Sardell, R., \& Soelberg, N. (2015). Reevaluating the speaking and listening demands of university classes for novice international students. ORTESOL Journal, 32, 1-12. 
Sherry, M., Thomas, P., \& Chui, W. H. (2010). Higher Education, 60(1), 33-46.

Swain, M. (2005). The output hypothesis: Theory and research. In E. Hinkel (Ed.), The handbook of research in second language teaching and learning (pp. 471-483). Mahwah, NJ: Lawrence Erlbaum.

Swain, M. (2013). The inseparability of cognition and emotion in second language learning. Language Teaching, 46(2), 195-207.

Tang, M., \& Tian, J. (2015). Associations between Chinese EFL graduate students' beliefs and language learning strategies. International Journal of Bilingual Education and Bilingualism, 18(2), 131-152.

Ting-Toomey, S., Gu, L., \& Chi, R. (2007). Communicating across cultures. Shanghai, China: Shanghai Foreign Language Education Press.

Terui, S. (2012). Second language learners' coping strategy in conversations with native speakers. Journal of International Students, 2(2), 168-183.

Torbiörn, I. (1982). Living abroad: Personal adjustment and personnel policy in the overseas setting. New York, NY: John Wiley \& Sons.

Wu, H. P., Garza, E., \& Guzman, N. (2015). International students' challenge and adjustment to college. Education Research International, 1-9.

Wu, W. C. V., Yen, L. L., \& Marek, M. (2011). Using online EFL interaction to increase confidence, motivation, and ability. Educational Technology \& Society, 14(3), 118-129.

Yashima, T., \& Tanaka, T. (2001). Roles of social support and social skills in the intercultural adjustment of Japanese adolescent sojourners in the USA. Psychological Reports, 88, 1201-1210.

Zhiping, D., \& Paramasivam, S. (2013). Anxiety of speaking English in class among international students in Malaysian university. International Journal of Education and Research, 1(11), 1-16.

I-CHING WANG, Ed.D., is an instructional designer. She earned her Ed.D. in Instructional Technology \& Media from Teachers College, Columbia University and M.S.Ed. in Teaching English to Speakers of Other Languages from University of Pennsylvania. Her research interests include intercultural communication, motivation, and second language acquisition. Specifically, she investigates how social-psychological interventions (attributional retraining and self-affirmation) can be employed to improve ESL learners' communication with native English speakers.Email: iw2121@tc.columbia.edu

JANET N. AHN, Ph.D., is an Assistant Professor of Psychology at William Paterson University. She earned both her Ph.D. and M.A. in Social Psychology from New York University. Broadly, her research interests are motivation and selfregulation. Specifically, she examines the interpersonal aspects of goal pursuit through projection, transference, and stereotyping in various settings, such as in education, in close relationships, and social interactions. Email: ahnj9@wpunj.edu

HYOJIN J. KIM, M.A., is a graduate student of Teachers College, Columbia University. She completed her studies in the Department of Human Development with the emphasis in Cognitive Studies in Education. She is a current administrator at an international school in Dallas, Texas. She has been an avid researcher and an 
educator with the interest in facilitating the adjustment of international students in the secondary education in the United States. Email: hk2805@tc.columbia.edu

XIAODONG LIN-SIEGLER, Ph.D., is a faculty in Cognitive Science in Education at Teachers College, Columbia University. She holds Ph.D. in Instructional psychology and Computer Education from Purdue University. She studies how history of scientists can be used to motivate students to solve challenging problems in schools. She also studies barriers to international students' learning in the United States and ways to remove these barriers. Her work have appeared in over 30 news media globally, including CBS.com News, PBS Kids, NPR Morning News Edition, Science, New York Times, Quartz magazine, BBC News, Australia Network News, News India, and China's People's Daily. Email: xlin@tc.columbia.edu

Manuscript submitted: May 17, 2016

Manuscript revised: October 21, 2016 Accepted for publication: October 28, 2016 